\title{
Factors associated with primary nonadherence to newly initiated direct oral anticoagulants in patients with nonvalvular atrial fibrillation
}

\author{
Alethea Charlton, MPharm, PgCert, MSc; Xavier Vidal, MD, PhD; Mònica Sabaté, MD, PhD; Elena Ballarín, RN; \\ Lina María Leguízamo Martínez, MD; and Luisa Ibáñez, MD, PhD
}

\section{What is already known about this subject}

- The number of patients with nonvalvular atrial fibrillation (NVAF) who are prescribed direct oral anticoagulants (DOACs) is increasing.

- Primary nonadherence, defined as failing to collect the initial prescription, is the first step to achieving effective drug therapy, yet it remains relatively unexplored in DOACs, with most drug utilization studies focusing on other adherence measures such as discontinuation or proportion of days covered.

- One recent study found that $10.8 \%$ of patients were primary nonadherent to DOACs.

\section{What this study adds}

- From 12,257 patients identified as being newly prescribed a DOAC in primary care, $10.4 \%(1,276)$ were primary nonadherent, failing to collect the first prescription during the treatment episode.

- Multivariable logistic regression showed higher odds of primary nonadherence for patients prescribed apixaban $(\mathrm{OR}=1.61,95 \% \mathrm{Cl}=1.39-1.87)$ or rivaroxaban $(\mathrm{OR}=1.28,95 \% \mathrm{Cl}=1.11$ 1.47) compared to dabigatran.

- Diagnosis of chronic kidney disease was associated with primary nonadherence ( $\mathrm{OR}=1.27,95 \% \mathrm{Cl}=1.08-1.50)$, while diabetes $(\mathrm{OR}=0.85,95 \% \mathrm{Cl}=0.74-0.97)$, hypertension $(\mathrm{OR}=0.79,95 \% \mathrm{Cl}=0.70$ 0.91 ), and stroke/transient ischemic attack $(\mathrm{OR}=0.70,95 \% \mathrm{Cl}=0.59-0.82)$ were associated with lower odds of primary nonadherence, as was at least 80 years of age compared to less than 65 years of age $(O R=0.78,95 \%$ $\mathrm{Cl}=0.66-0.93)$.

\section{Author affiliations}

Alethea Charlton, MPharm, PgCert, MSc, Fundació Institut Català de Farmacologia (FICF), Hospital Vall d'Hebron, Barcelona, Spain; Institute for Medical Information Processing, Biometry and Epidemiology, LMU Munich, Munich, Germany; and Pettenkofer School of Public Health, Munich, Germany. Xavier Vidal, MD, PhD; Mònica Sabaté, MD, PhD; and Luisa Ibáñez, MD, PhD, Fundació Institut Català de Farmacologia (FICF), Hospital Vall d'Hebron; Autonomous University of Barcelona; and Clinical Pharmacology Department, Vall d'Hebron University Hospital, Barcelona, Spain. Elena Ballarín, RN, Fundació Institut Català de Farmacologia (FICF) and Clinical Pharmacology Department, Vall d'Hebron University Hospital, Barcelona, Spain. Lina María Leguízamo Martínez, MD, Autonomous University of Barcelona and Clinical Pharmacology Department, Vall d'Hebron University Hospital, Barcelona, Spain.

\section{AUTHOR CORRESPONDENCE:}

Alethea Charlton, +44 742.763.9790;

aletheacharlton@gmail.com 


\section{ABSTRACT}

BACKGROUND: Direct oral anticoagulants (DOACs) are widely used for the prevention of stroke in nonvalvular atrial fibrillation (NVAF); however, real-world primary nonadherence (failing to collect the first prescription) has been measured in very few studies.

OBJECTIVE: To report primary nonadherence in NVAF patients who are newly prescribed DOACs and identify associated factors.

METHODS: This observational retrospective cohort study used a large primary care database in Catalonia. Patients with NVAF who were newly prescribed a DOAC between January 2009 and December 2015 were identified, and primary nonadherence was measured by comparing prescribing records to pharmacy claims data. Multivariable logistic regression was used to determine associated factors.

RESULTS: A total of 12,257 patients met the inclusion and exclusion criteria; of these, 1,276 (10.4\%) were primary nonadherent. Primary nonadherence was found to be $12.8 \%$ for apixaban, $8.6 \%$ for dabigatran, and $10.8 \%$ for rivaroxaban. Multivariable logistic regression indicated higher odds of primary nonadherence with apixaban and rivaroxaban compared to dabigatran (apixaban: $\mathrm{OR}=1.61,95 \%$ $\mathrm{Cl}=1.39-1.87$; rivaroxaban: $\mathrm{OR}=1.28,95 \% \mathrm{Cl}=1.11-1.47)$. Patients aged at least 80 years showed lower odds of primary nonadherence compared to those aged less than 65 years $(O R=0.78,95 \%$ $\mathrm{Cl}=0.66-0.93)$. A diagnosis of chronic kidney disease was associated with primary nonadherence $(\mathrm{OR}=1.27,95 \% \mathrm{Cl}=1.08-1.50)$. Whereas, diabetes $(\mathrm{OR}=0.85,95 \% \mathrm{Cl}=0.74-0.97)$, hypertension $(\mathrm{OR}=0.79,95 \%$ $\mathrm{Cl}=0.70-0.91)$, and stroke/transient ischemic attack (OR=0.70, 95\% $\mathrm{Cl}=0.59-0.82$ ) were inversely associated with primary nonadherence.

CONCLUSIONS: Overall, $10.4 \%$ of patients prescribed DOACs were primary nonadherent, failing to collect the first prescription. The percentage could have serious implications for patient outcomes and the real-world cost-effectiveness of prescribing DOACs in NVAF. Rates of primary nonadherence and associated factors may provide useful information for the design and evaluation of adherence interventions.

Nonadherence to medicines is a widely acknowledged problem that limits the effectiveness of treatments and results in poor patient outcomes, including increased mortality, ${ }^{1-4}$ hospitalization, ${ }^{5,6}$ and higher healthcare costs. ${ }^{6-8}$ Direct oral anticoagulants (DOACs) are increasingly used for the prevention of stroke in patients with nonvalvular atrial fibrillation (NVAF). ${ }^{9,10}$ In addition to the potential clinical implications of nonadherence, when compared to vitamin $\mathrm{K}$ antagonists (VKAs), ${ }^{11,12}$ adherence to DOACs is a subject of particular interest in light of their reduced monitoring requirements and shorter half-lives.

The use of pharmacy claims databases has expanded our ability to conduct large-scale real-world adherence studies.
Thus far, however, drug utilization research on DOACs has mainly focused on other adherence measures such as persistence,,$^{13-19}$ proportion of days covered, ${ }^{16,17,20-24}$ or medicine possession ratio. ${ }^{15,25,26}$

Primary nonadherence, defined as failing to collect the first prescription of a medicine, is the first step to achieving effective treatment. Estimates of primary nonadherence to medicines vary widely. ${ }^{27}$ One large study found that $28.3 \%$ of patients were primary nonadherent to new medicines, with medication class as a strong predictor of primary adherence. The study also found that medicines for chronic diseases have particularly poor primary adherence rates. ${ }^{28}$ Primary nonadherence has been associated with worse patient outcomes, including higher rates of mortality following myocardial infarction ${ }^{2}$ and worse control of hemoglobin A1c in diabetes. ${ }^{29}$ The reasons for not collecting a prescription may be complex, with possible causes including cost, concern about the medicine, and the perception that the medicine is not necessary. ${ }^{27}$

Primary nonadherence to DOACs remains relatively unexplored. Although, one recent study found the rate of nonadherence to DOACs to be $10.8 \%{ }^{30}$ The same study, which included VKAs and DOACs, found that primary nonadherence was associated with the type of anticoagulant prescribed, foreign nationality, dementia, and higher coinsurance in older age groups. Lower odds of primary nonadherence were found for patients with liver disease, those taking over six concomitant medicines, or whose prescriptions were transmitted electronically.

Information about the rate of primary nonadherence to DOACs can help elucidate the real-world cost-effectiveness of these medicines and highlight a key area for adherence interventions. Furthermore, identifying the determinants of nonadherence can serve as the basis for designing interventions to improve adherence and patient outcomes. This study uses pharmacy claims data from a large primary care database in Catalonia to measure the rate of primary nonadherence to newly prescribed DOACs in NVAF patients and to identify associated factors.

\section{Methods}

\section{DATA SOURCE}

All data for this study were obtained from the Information System for the Development of Research in Primary Care (SIDIAP), which contains primary care data for approximately 5.8 million people, covering $80 \%$ of the population of Catalonia, Northeast Spain. ${ }^{31}$ Catalonia has its own national health service, which provides medical care at primary care centers. The SIDIAP database was created with the goal 
of promoting research and contains anonymized patient information collected during clinical practice in primary care centers. The information includes demographics, diagnoses, medicines prescribed, and pharmacy claims' (reimbursement) details from patient collection at a community pharmacy. The Catalan national health service uses a formulary for prescribing and prescription costs. The costs are subsequently paid for by the health service, and patients are required to make some copayments. This study used the existing SIDIAP dataset from the cross-national DOAC utilization study by Ibáñez, et al. ${ }^{9}$ No ethics approval was required for this study.

\section{SETTING AND PARTICIPANTS}

Patients, aged 18 years or over, were included if they were prescribed a DOAC (apixaban, dabigatran or rivaroxaban) between January1, 2009 and December 31, 2015, without having any previous DOAC prescriptions in the prior 12 months. Only patients with a diagnosis of NVAF (ICD-10 diagnosis codes in Supplementary Table 1, available in online article) in the three months before or the three months after the DOAC prescription were included. Patients were excluded if they were in the database for fewer than 12 months before the index date (date of first DOAC prescription) or less than one month after the index date. As according to the method described by Gardarsdottir, et al, ${ }^{32}$ for each patient, the duration of the treatment was calculated as the time between the start and end date of consecutive DOAC prescriptions, allowing a grace period of up to 30 days between prescriptions. Patients were excluded if the treatment episode was less than one month in total, since it was unlikely that these shorter treatments were intended for the longterm prevention of stroke in NVAF.

\section{VARIABLES}

The outcome of interest was primary nonadherence, defined as the patient failing to collect the first prescription for a DOAC within the treatment episode. Primary nonadherence was established by comparing prescribing data to pharmacy claims data. A patient was considered to be primary nonadherent if they did not collect the index prescription during the treatment episode or in the month before, or the month after, the treatment episode. The reason for including one month of pharmacy claims data before the start date and after the end date of the treatment episode is to account for the fact that pharmacy claims data are reported on a monthly basis. ${ }^{88}$

The secondary aim was to identify factors associated with primary nonadherence. Covariates considered included patient age at index date, sex, DOAC prescribed (apixaban, dabigatran or rivaroxaban), and dosing frequency.
The factors were selected based on literature review of other primary nonadherence studies and the availability of covariates within the existing data. Age groups $(<65,65-74$, 75-79 and $\geq 80$ years) were chosen to aid comparison with the cross-national DOAC usage study by Ibáñez, et al. ${ }^{9}$

Comorbidities considered as covariates were alcohol abuse, cancer, chronic kidney disease (CKD), dementia, diabetes, gastric bleed, gastric ulcer, heart failure, hypertension, liver disease, respiratory disease, stroke/transient ischemic attack (TIA), and other cardiovascular (CV) disease. Other CV disease was a composite variable, which included angina, myocardial infarction, ischemic heart disease, and atherosclerosis (diagnosis codes provided in the Supplementary Table 2, available in online article). CKD was identified through presence of a diagnosis code, as laboratory measurement of renal function was not available for all patients. Patients were considered to have a comorbidity if there was a diagnosis on the index date or on any date prior to the index date. In light of the unavailable diagnosis of depression in the dataset, concomitant prescribing of selective serotonin reuptake inhibitors (SSRIs) or serotonin and noradrenaline reuptake inhibitors (SNRIs) was considered a covariate.

The available dataset contained prescribing details of around 700 medicines other than DOACs (specified in Supplementary Table 3, available in online article). The data, although not an exhaustive list of all medicines that patients were prescribed, was used to construct a polypharmacy variable by counting the number of unique medicines currently being prescribed to patients on the index date. Polypharmacy was grouped into three categories $(\leq 4,5-9$ and $\geq 10$ medicines) to reflect commonly used definitions in the literature. ${ }^{33}$ All codes used to identify diagnoses and concomitant medicines are specified in the Supplementary Materials, available in online article.

\section{STATISTICAL ANALYSIS}

The baseline characteristics of the cohort were described, stratified by individual DOAC (apixaban, dabigatran or rivaroxaban). Bivariate analysis was performed for primary nonadherence and each covariate for all DOACs and for each individual DOAC; the Chi-squared test was used for categorical variables and the Cochran-Armitage trend test for ordinal variables. Fisher's exact test was used when the expected count of a variable was less than 5 (sensitivity analyses only). Multivariable logistic regression was used to examine factors associated with primary nonadherence. Variables with a two-sided $P$ value less than 0.05 were included in the final parsimonious model. A c-statistic was used to assess goodness of fit. 


\section{FIGURE 1 Study Attrition Showing Inclusion and Exclusion Criteria}

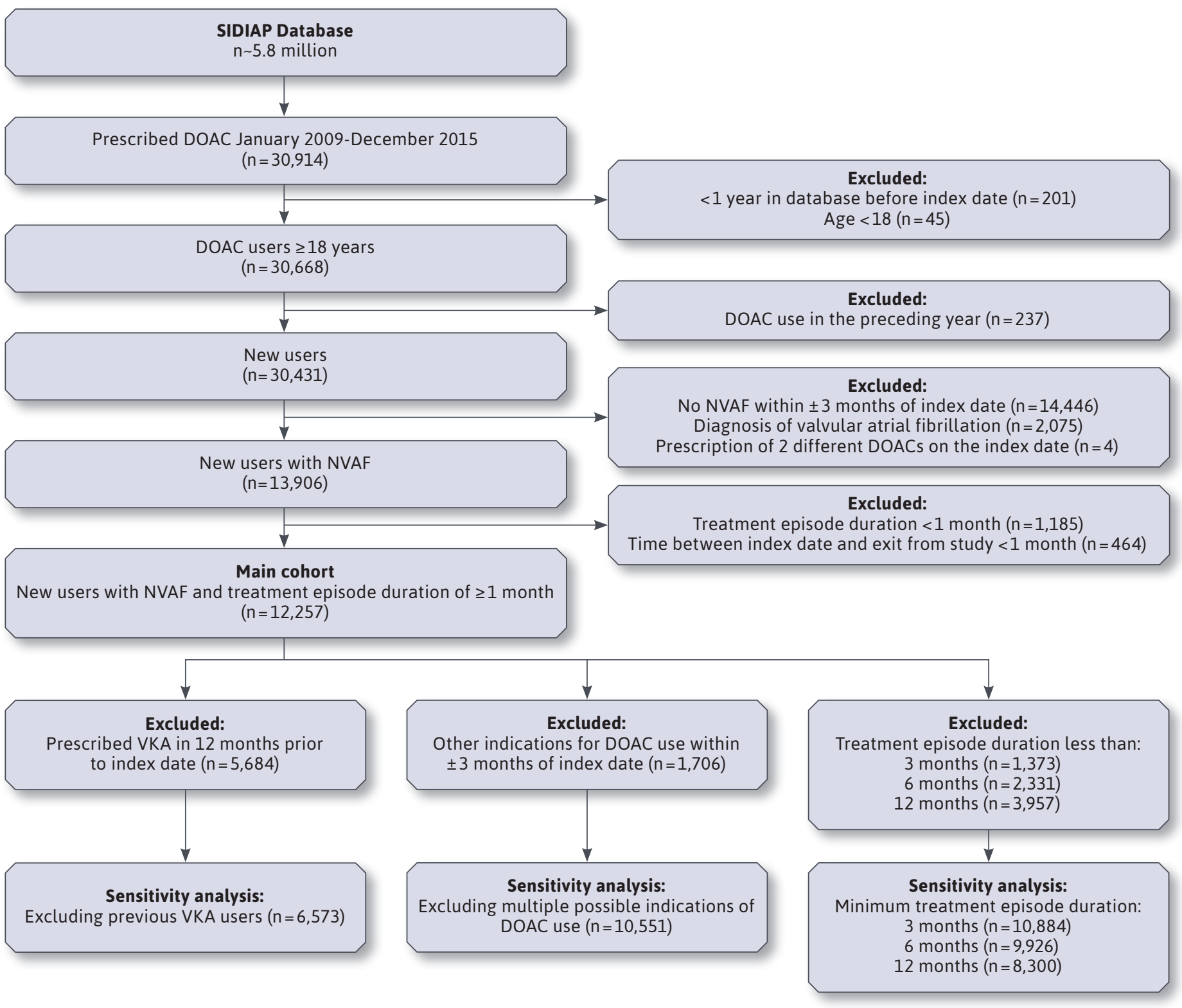

$D O A C=$ direct oral anticoagulant; NVAF=nonvalvular atrial fibrillation; SIDIAP =System for the Development of Research in Primary Care

VKA = vitamin $K$ antagonist.

Sensitivity analyses were performed in which patients were excluded from the main cohort. Firstly, patients who had pharmacy claims data for a VKA in the 12 months prior to the index date were excluded. To account for the fact that DOACs are licensed for indications other than NVAF, a second sensitivity analysis excluded patients with multiple indications for DOAC use within three months before and after the index date (based on other licensed indications for DOACs during the study period, specified in Supplementary Table 1). Finally, sensitivity analyses were performed in 


\section{TABLE 1 Baseline Characteristics by Type of Direct Oral Anticoagulant}

\begin{tabular}{|c|c|c|c|c|}
\hline & $\begin{array}{c}\text { All } \\
\%(n)\end{array}$ & $\begin{array}{c}\text { Apixaban } \\
\%(n)\end{array}$ & $\begin{array}{c}\text { Dabigatran } \\
\%(\mathbf{n})\end{array}$ & $\begin{array}{c}\text { Rivaroxaban } \\
\%(n)\end{array}$ \\
\hline Total & 12,257 & 2,910 & 4,781 & 4,566 \\
\hline$\%$ & & 23.7 & 39.0 & 37.3 \\
\hline \multicolumn{5}{|l|}{ Sex } \\
\hline Male & $53.6 \quad(6,570)$ & $52.9 \quad(1,540)$ & $54.7 \quad(2,613)$ & $52.9 \quad(2,417)$ \\
\hline Female & $46.4 \quad(5,687)$ & $47.1 \quad(1,370)$ & $45.3 \quad(2,168)$ & $47.1 \quad(2,149)$ \\
\hline
\end{tabular}

Age (years)

\begin{tabular}{l|rr|rr|rr|rr}
\hline Mean (SD) & 74.6 & $(11.0)$ & 76.2 & $(10.5)$ & 73.6 & $(10.9)$ & 74.5 & $(11.2)$ \\
\hline$<65$ & 16.7 & $(2,048)$ & 13.0 & $(378)$ & 18.8 & $(898)$ & 16.9 & $(772)$ \\
\hline $65-74$ & 26.8 & $(3,285)$ & 24.6 & $(717)$ & 28.4 & $(1,358)$ & 26.5 & $(1,210)$ \\
\hline $75-79$ & 18.6 & $(2,280)$ & 17.8 & $(518)$ & 19.1 & $(915)$ & 18.6 & $(847)$ \\
\hline$\geq 80$ & 37.9 & $(4,644)$ & 44.6 & $(1,297)$ & 33.7 & $(1,610)$ & 38.0 & $(1,737)$ \\
\hline
\end{tabular}

Treatment episode duration (months)

\begin{tabular}{l|rr|rr|rr|rr}
\hline Mean (SD) & 22.3 & $(16.7)$ & 19.4 & $(11.9)$ & 25.2 & $(19.9)$ & 21.2 & $(15.2)$ \\
\hline $1-2$ & 11.2 & $(1,373)$ & 8.6 & $(251)$ & 12.6 & $(601)$ & 11.4 & $(521)$ \\
\hline $3-5$ & 7.8 & $(958)$ & 7.0 & $(203)$ & 8.1 & $(387)$ & 8.1 & $(368)$ \\
\hline $6-11$ & 13.3 & $(1,626)$ & 14.9 & $(433)$ & 12.8 & $(612)$ & 12.7 & $(581)$ \\
\hline$\geq 12$ & 67.7 & $(8,300)$ & 69.5 & $(2,023)$ & 66.5 & $(3,181)$ & 67.8 & $(3,096)$ \\
\hline
\end{tabular}

Dosing frequency

\begin{tabular}{l|rr|rr|rr|rr}
\hline No data & 1.1 & $(132)$ & 1.0 & $(30)$ & 1.1 & $(51)$ & 1.1 & $(51)$ \\
\hline Once daily & 43.0 & $(5,272)$ & 6.7 & $(196)$ & 12.9 & $(617)$ & 97.7 & $(4,459)$ \\
\hline Twice daily & 55.9 & $(6,853)$ & 92.2 & $(2,684)$ & 86.0 & $(4,113)$ & 1.2 & $(56)$ \\
\hline
\end{tabular}

Polypharmacy (number of concomitant medicines ${ }^{\mathrm{a}}$ )

\begin{tabular}{l|rr|rr|rr|rr}
\hline Mean (SD) & 3.3 & $(1.9)$ & 3.5 & $(2.0)$ & 3.1 & $(1.9)$ & 3.3 & $(1.9)$ \\
\hline$\leq 4$ & 75.8 & $(9,291)$ & 72.0 & $(2,094)$ & 79.3 & $(3,789)$ & 74.6 & $(3,408)$ \\
\hline $5-9$ & 23.8 & $(2,919)$ & 27.6 & $(803)$ & 20.4 & $(973)$ & 25.0 & $(1,143)$ \\
\hline$\geq 10$ & 0.4 & $(47)$ & 0.4 & $(13)$ & 0.4 & $(19)$ & 0.3 & $(15)$ \\
\hline
\end{tabular}

Concomitant medicines ${ }^{\mathrm{a}}$

\begin{tabular}{|c|c|c|c|c|c|c|c|c|}
\hline SSRI/SNRI & 15.0 & $(1,841)$ & 15.6 & (455) & 14.2 & (679) & 15.5 & (707) \\
\hline \multicolumn{9}{|l|}{ Previous VKA use } \\
\hline Previous VKA use & 46.4 & $(5,684)$ & 51.1 & $(1,488)$ & 42.0 & $(2,006)$ & 48.0 & $(2,190)$ \\
\hline
\end{tabular}

continued on next page

which the minimum treatment episode duration required for inclusion in the analysis was increased from one month to three, six and 12 months. All analyses were performed using SAS Enterprise Guide version 7.15.

\section{Results}

\section{BASELINE CHARACTERISTICS}

A total of 12,257 patients were included in the cohort; Figure 1 shows how they were identified. The baseline characteristics for the whole cohort and for each DOAC are shown in Table 1. Apixaban, dabigatran and rivaroxaban were respectively prescribed to 2,910 (23.7\%), 4,781 (39.0\%) and 4,566 (37.3\%) patients. The majority of patients in the cohort were male (53.6\%) and the mean age was 74.6 years (standard deviation $=11.0$ years), with the largest age group being at least 80 years old (37.9\%). Previous use of a VKA was identified for $46.4 \%$ of patients. The most common comorbidities were hypertension (72.6\%) and diabetes (29.2\%). Characteristics were similar across the three DOACs. Although, there were more patients with previous VKA use in the apixaban group (51.1\%) than in the dabigatran (42.0\%) and rivaroxaban (48.0\%) groups. Apixaban and dabigatran were more often prescribed twice a day $(92.2 \%$ and $86.0 \%$, respectively), while rivaroxaban was more often prescribed once a day (97.7\%). Frequency data were missing for 132 patients (1.1\%), who were excluded from subsequent analyses using the dosing frequency variable.

\section{PRIMARY NONADHERENCE}

Primary nonadherence in the main cohort was $10.4 \%$. Table 2 shows the rates of primary nonadherence and the results of the bivariate analysis for all DOACs (results for individual DOACs can be found in the Supplementary Material, available in online article). Differences were observed between the different DOACs: apixaban had the highest rate of primary nonadherence (12.8\%), followed by rivaroxaban (10.8\%), and dabigatran (8.6\%). Overall, there was a greater proportion of younger patients (<65 years) among the nonadherent patients $(20.3 \%$, $\mathrm{P}=0.0013)$. Nonadherent patients also had a higher prevalence of CKD $(16.5 \%$ vs $14.4 \%, P=0.0389$ ) and a lower prevalence of diabetes $(25.9 \%$ vs $29.6 \%$ $\mathrm{P}=0.0052)$, hypertension $(67.4 \%$ vs $73.2 \%, \mathrm{P}<0.0001)$, other $\mathrm{CV}$ disease 


\section{TABLE 1}

Baseline Characteristics by Type of Direct Oral Anticoagulant (continued)

\begin{tabular}{|c|c|c|c|c|c|c|c|c|}
\hline \multirow[b]{2}{*}{ Comorbidities $^{b}$} & \multicolumn{2}{|c|}{$\begin{array}{l}\text { All } \\
\%(n)\end{array}$} & \multicolumn{2}{|c|}{$\begin{array}{c}\text { Apixaban } \\
\%(n)\end{array}$} & \multicolumn{2}{|c|}{$\begin{array}{c}\text { Dabigatran } \\
\%(n)\end{array}$} & \multicolumn{2}{|c|}{$\begin{array}{c}\text { Rivaroxaban } \\
\%(n)\end{array}$} \\
\hline & & & & & & & & \\
\hline Alcohol abuse & 3.9 & $(484)$ & 4.3 & (125) & 3.8 & (182) & 3.9 & (177) \\
\hline Cancer & 13.6 & $(1,665)$ & 15.4 & (447) & 12.6 & (604) & 13.4 & (614) \\
\hline CKD & 14.6 & $(1,790)$ & 21.5 & (626) & 9.9 & (472) & 15.2 & (692) \\
\hline Dementia & 4.7 & $(580)$ & 5.1 & (148) & 3.9 & (187) & 5.4 & (245) \\
\hline Diabetes & 29.2 & $(3,583)$ & 32.2 & (937) & 27.5 & $(1,317)$ & 29.1 & $(1,329)$ \\
\hline Gastric bleed & 5.0 & $(607)$ & 6.4 & (186) & 4.4 & (208) & 4.7 & (213) \\
\hline Gastric ulcer & 7.4 & (909) & 8.8 & (255) & 6.5 & (313) & 7.5 & (341) \\
\hline Heart failure & 19.0 & $(2,326)$ & 24.5 & (714) & 16.3 & (779) & 18.2 & (833) \\
\hline Hypertension & 72.6 & $(8,899)$ & 75.2 & $(2,188)$ & 70.8 & $(3,384)$ & 72.9 & $(3,327)$ \\
\hline Liver disease & 7.3 & $(891)$ & 8.5 & (248) & 6.7 & (320) & 7.1 & (323) \\
\hline Other CV disease & 22.1 & $(2,709)$ & 25.6 & (744) & 20.0 & (956) & 22.1 & $(1,009)$ \\
\hline Respiratory disease & 24.3 & $(2,979)$ & 27.8 & (809) & 21.5 & $(1,030)$ & 25.0 & $(1,140)$ \\
\hline Stroke/TIA & 21.6 & $(2,651)$ & 26.7 & (777) & 21.9 & $(1,045)$ & 18.2 & (829) \\
\hline \multicolumn{9}{|c|}{ Renal function (mL/min) } \\
\hline$>80$ & 15.7 & $(1,920)$ & 14.3 & (416) & 16.4 & (783) & 15.8 & (721) \\
\hline $50-80$ & 19.1 & $(2,337)$ & 20.0 & (583) & 18.8 & (899) & 18.7 & (855) \\
\hline $30-49$ & 9.4 & $(1,153)$ & 13.5 & (394) & 6.8 & (327) & 9.5 & (432) \\
\hline $15-29$ & 1.7 & (206) & 2.9 & (83) & 0.8 & (38) & 1.9 & (85) \\
\hline$<15$ & 0.0 & (2) & 0.1 & (2) & 0.0 & (0) & 0.0 & (0) \\
\hline No data & 54.2 & $(6,639)$ & 49.2 & $(1,432)$ & 57.2 & $(2,734)$ & 54.2 & $(2,473)$ \\
\hline
\end{tabular}

aConcomitant medicines according to codes in Supplementary Materials.

${ }^{b}$ Comorbidities according to codes in Supplementary Materials.

$C K D=$ chronic kidney disease $; C V=$ cardiovascular; $S D=$ standard deviation; $S N R I=$ serotonin -

norepinephrine reuptake inhibitor; SSRI=selective serotonin reuptake inhibitor; $T I A=$ transient ischemic attack; VKA = vitamin $\mathrm{K}$ antagonist.

(19.7\% vs $22.4 \%, P=0.0270)$ and stroke/ TIA $(16.2 \%$ vs $22.3 \%, \mathrm{P}<0.0001)$.

\section{FACTORS ASSOCIATED WITH PRIMARY NONADHERENCE}

Results of the multivariable logistic regression are given in Table 3 and presented as a forest plot in Figure 2. Patients prescribed apixaban and rivaroxaban had greater odds of being primary nonadherent compared to those prescribed dabigatran (apixaban: OR=1.61, 95\% CI =1.39-1.87, $\mathrm{P}<0.0001 ; \quad$ rivaroxaban: $\mathrm{OR}=1.28$, 95\% $\mathrm{CI}=1.11-1.47, \quad \mathrm{P}=0.0005)$. Older age ( $\geq 80$ years) was associated with lower odds of primary nonadherence $(\mathrm{OR}=0.78,95 \% \mathrm{CI}=0.66-0.93$, $\mathrm{P}=0.0056)$, as was diagnosis of diabetes $(\mathrm{OR}=0.85,95 \% \mathrm{CI}=0.74-0.97$, $\mathrm{P}=0.0189)$, hypertension $(\mathrm{OR}=0.79$, 95\% CI $=0.70-0.91, \quad P=0.0006)$, and stroke $/$ TIA $(\mathrm{OR}=0.70,95 \% \mathrm{CI}=0.59$ $0.82, \mathrm{P}<0.0001)$. Diagnosis of CKD was associated with higher odds of primary nonadherence $(\mathrm{OR}=1.27,95 \%$ $\mathrm{CI}=1.08-1.50, \mathrm{P}=0.0046)$. Neither the other covariates that were examined, nor any of the interaction terms that were examined, showed significant association with primary nonadherence in the multivariable analysis; therefore, the covariates and interaction terms were not included in the final model. The c-statistic for the final model was 0.585 .

\section{SENSITIVITY ANALYSES}

Baseline characteristics across all sensitivity analyses were similar. Dabigatran was the most commonly prescribed DOAC across all analyses. A greater number of patients at least 80 years old was observed among patients with previous VKA use (42.5\%), compared to those with no previous VKA use (33.9\%). In the sensitivity analysis that excluded patients with multiple possible indications for DOAC use, there were higher rates of other CV disease among the excluded patients (75.4\%) when compared to the included patients (13.5\%). The higher rates are likely due to DOACs being licensed for some CV diseases, such as prevention of atherothrombotic events after an acute coronary syndrome.

The overall rates of primary nonadherence to DOACs in the sensitivity analyses ranged from $4.1 \%$ to $13.7 \%$. When patients with previous VKA use were excluded, primary nonadherence rose to $13.7 \%$. Following the exclusion of patients with other potential indications for DOAC use, primary nonadherence was the same as in the primary analysis (10.4\%). Increasing the minimum treatment episode duration required for inclusion reduced the rate of primary nonadherence to $8.2 \%, 7.2 \%$, and $4.1 \%$ respectively, for minimum treatment episode durations of 3, 6 and 12 months, respectively.

Apixaban had the highest level of primary nonadherence in all sensitivity analyses, except when the minimum treatment episode duration was extended to 12 months (apixaban: $4.1 \%$, dabigatran: $3.4 \%$, rivaroxaban: $4.7 \%)$. Factors associated with primary 


\begin{tabular}{|c|c|c|c|}
\hline & $\begin{array}{c}\text { All primary } \\
\text { nonadherent } \\
\%(n)\end{array}$ & $\begin{array}{c}\text { Primary } \\
\text { adherent } \\
\%(n)\end{array}$ & $P$ value \\
\hline Total & 1,276 & 10,981 & \\
\hline$\%$ & 10.4 & 89.6 & \\
\hline \multicolumn{4}{|l|}{ DOAC } \\
\hline Apixaban & $29.2 \quad(373)$ & $23.1(2,537)$ & \multirow{3}{*}{$<0.0001$} \\
\hline Dabigatran & $32.1 \quad(410)$ & $39.8(4,371)$ & \\
\hline Rivaroxaban & $38.6 \quad(493)$ & $37.1(4,073)$ & \\
\hline \multicolumn{4}{|l|}{ Sex } \\
\hline Male & $56.2 \quad(717)$ & $53.3(5,853)$ & \multirow{2}{*}{0.0501} \\
\hline Female & $43.8 \quad(559)$ & $46.7(5,128)$ & \\
\hline \multicolumn{4}{|l|}{ Age (years) } \\
\hline$<65$ & $20.3 \quad(259)$ & $16.3(1,789)$ & \multirow{4}{*}{0.0013} \\
\hline $65-74$ & $26.9 \quad(343)$ & $26.8(2,942)$ & \\
\hline $75-79$ & $17.2 \quad(220)$ & $18.8(2,060)$ & \\
\hline$\geq 80$ & $35.6 \quad(454)$ & $38.2(4,190)$ & \\
\hline \multicolumn{4}{|c|}{ Dosing frequency } \\
\hline Once daily & $42.4 \quad(541)$ & $43.1(4,731)$ & \multirow{2}{*}{0.5038} \\
\hline Twice daily & $53.1 \quad(678)$ & $56.2(6,175)$ & \\
\hline \multicolumn{4}{|c|}{ Polypharmacy (number of concomitant medicines ${ }^{a}$ ) } \\
\hline$\leq 4$ & $74.9 \quad(956)$ & $75.9 \quad(8,335)$ & \multirow{3}{*}{0.3346} \\
\hline $5-9$ & $24.5 \quad(312)$ & $23.7(2,607)$ & \\
\hline$\geq 10$ & 0.6 & $0.4 \quad(39)$ & \\
\hline
\end{tabular}

nonadherence in the multivariable models of the sensitivity analyses varied, although type of DOAC, hypertension and stroke/TIA remained present in all models. Full results of the sensitivity analyses are provided in the Supplementary Materials, available in online article.

\section{Discussion}

This primary adherence study used pharmacy claims data from a large primary care database in Catalonia to measure primary nonadherence to DOACs in patients with NVAF. This topic is relatively unexplored and, to our knowledge, ours is the first primary nonadherence study to focus solely on DOACs. The study used data included in the drug utilization study by Ibáñez, et al. ${ }^{9}$ and, as expected, baseline characteristics were very similar.
Our study found that $10.4 \%$ of patients were primary nonadherent and never filled their first DOAC prescription. There are very few studies with which to compare these results. The only other study to measure DOAC primary nonadherence that we have been able to identify found that $10.8 \%$ of patients were primary nonadherent to DOACs in a cohort that excluded previous users of VKAs. ${ }^{30}$ When patients with previous VKA use were excluded in our sensitivity analysis, the rate of primary nonadherence rose from $10.4 \%$ to $13.7 \%$. The increase is in line with the results of other studies, which show that patients who have previously used other anticoagulants have better adherence to a new DOAC, where proportion of days covered is used as the adherence measure. ${ }^{16,23}$

Apixaban showed higher primary nonadherence (12.8\%) than rivaroxaban $(10.8 \%)$ or dabigatran $(8.6 \%)$, and type of DOAC was the strongest predictor of adherence in the multivariable model. The data contrasts with the study by Rodriguez-Bernal, et al., ${ }^{30}$ which finds that rivaroxaban has the greatest level of primary nonadherence among DOACs (15.5\%), followed by dabigatran (7.9\%) and apixaban (5.0\%). Some of the differences observed between the two studies may be due to differing inclusion criteria, for example Rodriguez-Bernal, et al. ${ }^{30}$ include patients with all types of atrial fibrillation, rather than only patients with NVAF.

The reason for higher primary nonadherence to apixaban in our study remains unclear. Apixaban continued to have the highest level of primary nonadherence in all sensitivity analyses, except when the minimum treatment episode duration was extended to 12 months. For this analysis, the differences in primary nonadherence rate between the DOACs were smaller, and rivaroxaban had the highest primary nonadherence rate (apixaban: $4.3 \%$, dabigatran: $3.4 \%$, rivaroxaban: $4.7 \%$ ).

Older age has been linked to improved primary adherence to new medicines, ${ }^{34}$ an association that was also found in our study. The association appears to be in line with other DOAC utilization studies, which have found that older patients have better persistence ${ }^{17,19}$ and adherence according to proportion of days covered. ${ }^{16,24} \mathrm{~A}$ contributing factor to this finding in our study could be that pensioners are required to pay lower copayment costs than nonpensioners.

The comorbidities associated with reduced levels of primary nonadherence in the multivariable logistic regression were diabetes, hypertension, and stroke/TIA, while CKD was associated with higher levels of primary nonadherence. Of these, hypertension and stroke/TIA continued to be significant across all sensitivity analyses. These associated factors contrast starkly with the study by Rodriguez-Bernal, et $\mathrm{al},{ }^{30}$ which found that dementia, non-Spanish European 


\section{TABLE 2}

Primary Nonadherence for All Direct Oral Anticoagulants (continued)

\begin{tabular}{|c|c|c|c|c|}
\hline & \multicolumn{2}{|c|}{$\begin{array}{c}\text { All primary } \\
\text { nonadherent } \\
\%(n)\end{array}$} & $\begin{array}{c}\text { Primary } \\
\text { adherent } \\
\%(n)\end{array}$ & $P$ value \\
\hline \multicolumn{5}{|c|}{ Concomitant medicines $^{a}$} \\
\hline SSRI/SNRI & 14.7 & $(187)$ & $15.1(1,654)$ & 0.7000 \\
\hline \multicolumn{5}{|l|}{ Comorbidities $^{b}$} \\
\hline Alcohol abuse & 4.0 & $(51)$ & $3.9 \quad(433)$ & 0.9257 \\
\hline Cancer & 13.3 & $(170)$ & $13.6(1,495)$ & 0.7736 \\
\hline CKD & 16.5 & $(211)$ & $14.4(1,579)$ & 0.0389 \\
\hline Dementia & 4.8 & $(61)$ & $4.7 \quad(519)$ & 0.9312 \\
\hline Diabetes & 25.9 & $(330)$ & $29.6(3,253)$ & 0.0052 \\
\hline Gastric bleed & 5.8 & (74) & $4.9 \quad(533)$ & 0.1406 \\
\hline Gastric ulcer & 7.3 & $(93)$ & $7.4 \quad(816)$ & 0.8540 \\
\hline Heart failure & 18.3 & $(233)$ & $19.1(2,093)$ & 0.4903 \\
\hline Hypertension & 67.4 & $(860)$ & $73.2(8,039)$ & $<0.0001$ \\
\hline Liver disease & 7.7 & $(98)$ & $7.2 \quad(793)$ & 0.5503 \\
\hline Other CV disease & 19.7 & $(251)$ & $22.4(2,458)$ & 0.0270 \\
\hline Respiratory disease & 24.4 & $(311)$ & $24.3(2,668)$ & 0.9519 \\
\hline Stroke/TIA & 16.2 & $(207)$ & $22.3(2,444)$ & $<0.0001$ \\
\hline
\end{tabular}

${ }^{a}$ Concomitant medicines according to codes in Supplementary Materials.

${ }^{b}$ Comorbidities according to codes in Supplementary Materials.

$C K D=$ chronic kidney disease $C V=$ cardiovascular $D O A C=$ direct oral

anticoagulant; SNRI = serotonin-norepinephrine reuptake inhibitor;

$S S R I=$ selective serotonin reuptake inhibitor; $T I A=$ transient ischemic attack.

nationality, and higher coinsurance in older age groups were associated with higher odds of primary nonadherence to DOACs and VKAs; whereas, liver disease, polypharmacy, and electronic transmission of the prescription to the pharmacy gave lower odds of primary nonadherence. Perhaps these differences are not surprising, given that secondary DOAC adherence studies also show a lack of consensus in factors influencing adherence. ${ }^{12}$ It should also be noted that the factors evaluated in our study were not identical to those in the study by Rodriguez-Bernal, et al..$^{30}$ Furthermore, primary adherence may be affected by more nuanced factors that were not investigated in our study, such as the patient's understanding of their condition and quality of interactions between patients and prescribers. Indeed, a study including 67 prescribing sites found that, according to the proportion of days covered, sites that provided mandatory pharmacist led education and adherence monitoring had a higher proportion of patients with good dabigatran adherence. ${ }^{35}$
TABLE 3 Multivariable Logistic Regression Model of Factors Associated with Primary Nonadherence

\begin{tabular}{|c|c|c|c|c|}
\hline & Odds ratio & $\begin{array}{l}95 \% \mathrm{Cl} \\
\text { (lower) }\end{array}$ & $\begin{array}{l}95 \% \mathrm{Cl} \\
\text { (upper) }\end{array}$ & $P$ value \\
\hline \multicolumn{5}{|c|}{ DOAC (ref = dabigatran) } \\
\hline Apixaban & 1.61 & 1.39 & 1.87 & $<0.0001$ \\
\hline Rivaroxaban & 1.28 & 1.11 & 1.47 & 0.0005 \\
\hline \multicolumn{5}{|c|}{ Age (years; ref $=<65$ ) } \\
\hline $65-74$ & 0.85 & 0.72 & 1.02 & 0.0766 \\
\hline $75-79$ & 0.80 & 0.65 & 0.97 & 0.0216 \\
\hline$\geq 80$ & 0.78 & 0.66 & 0.93 & 0.0056 \\
\hline \multicolumn{5}{|c|}{ Comorbidities $^{\mathrm{a}}(\mathrm{ref}=$ none) } \\
\hline CKD & 1.27 & 1.08 & 1.50 & 0.0046 \\
\hline Diabetes & 0.85 & 0.74 & 0.97 & 0.0189 \\
\hline Hypertension & 0.79 & 0.70 & 0.91 & 0.0006 \\
\hline Stroke/TIA & 0.70 & 0.59 & 0.82 & $<0.0001$ \\
\hline
\end{tabular}

${ }^{a}$ Comorbidities according to codes in Supplementary Materials.

$\mathrm{Cl}=$ confidence interval; $C K D=$ chronic kidney disease $; D O A C=$ direct oral anticoagulant; $T I A=$ transient ischemic attack.

Sensitivity analyses showed that overall primary nonadherence to DOACs reduced as the minimum treatment episode was extended, from $10.4 \%$ for patients with treatment episodes of at least one month to $4.1 \%$ for patients with treatment episodes of at least 12 months. It is possible that patients with shorter treatment episodes were prescribed DOACs for indications other than long-term use in NVAF and, therefore, had different characteristics. However, when patients with multiple possible indications for DOAC use were excluded in a sensitivity analysis, the baseline characteristics were very similar to those of the main cohort and the rate of primary nonadherence remained at $10.4 \%$.

Our study utilized real-world data to assess primary nonadherence and is supported by various sensitivity analyses to investigate the effects of changes to inclusion criteria. Medicines in Catalonia are paid for by the health service, with patients being required to make some copayments. Medicine payment by the health service avoids a limitation of studies using health insurance claims in which a small number of medicines paid for in cash by the patient would appear as primary nonadherent due to the absence of associated claims data. ${ }^{36}$ Given that higher medicine copayments or costs could be factors that affect primary nonadherence, differences in medicine payments should be considered when attempting to generalize this study's 


\section{FIGURE 2 Forest Plot of Factors Associated with Primary Nonadherence in Multivariable Logistic Regression Model}

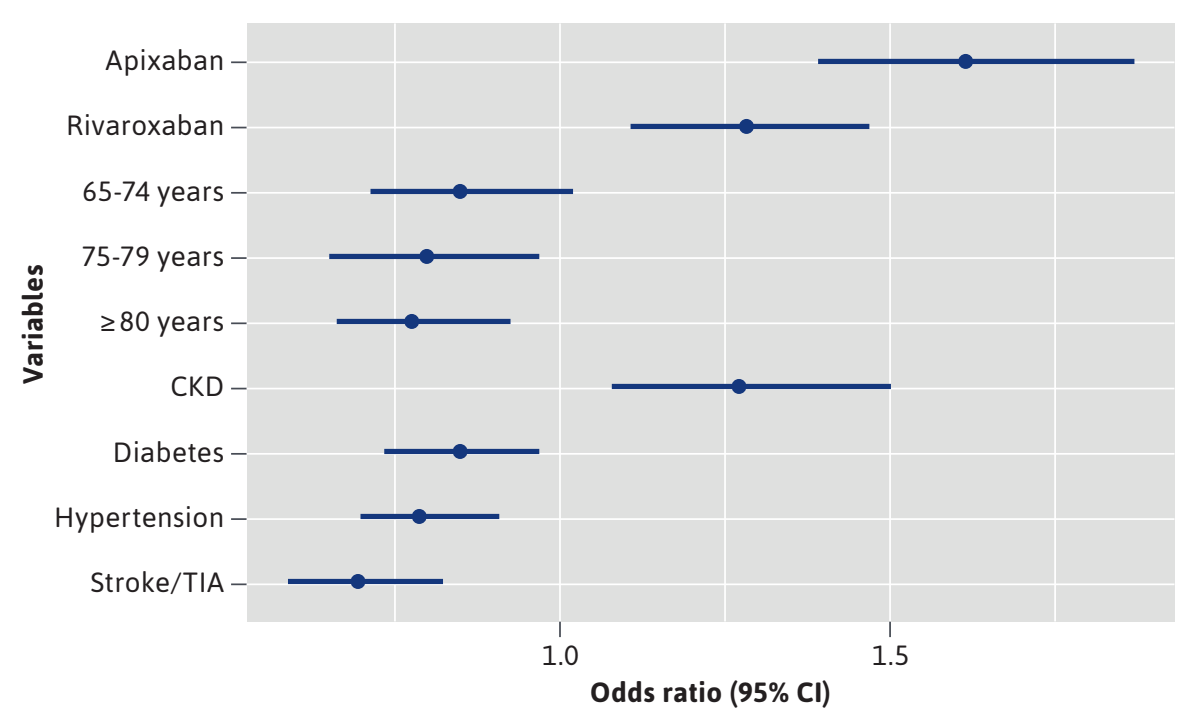

$C K D=$ chronic kidney disease $; \mathrm{TIA}=$ transient ischemic attack.
Finally, we note that, while multivariable logistic regression identified several factors associated with primary nonadherence, the overall goodness of fit to the model remained low $(\mathrm{c}=0.585)$. Sensitivity analysis revealed that, despite changes in inclusion criteria, type of DOAC, hypertension, and stroke/TIA remained correlated with primary nonadherence across all analyses; however, whether these associations are causative cannot be determined from our observational study.

\section{Conclusions}

Prescribing of DOACs to prevent stroke in patients with NVAF is increasing; however, our study indicates that around one in 10 patients are primary nonadherent and fail to even commence taking the prescribed medicine. This failure could have serious implications for the cost-effectiveness of prescribing DOACs. Furthermore, the impact of primary nonadherence to these medicines on patient outcomes has not yet been quantified. Our study also showed several factors that may influence primary nonadherence, including which DOAC is prescribed, age, and diagnosis of CKD, diabetes, hypertension, or stroke/TIA. These results highlight a key opportunity to design interventions targeting primary nonadherence. Moreover, primary nonadherent patients may never visit the community pharmacies where many adherence interventions currently take place. 


\section{DISCLOSURES}

No outside funding was received for this study. The data for this study came from the European Medicines Agency PE-PV project (Grant/Award Number EMA/2015/27/PH). The authors have nothing to disclose.

A preliminary version of this work was presented at the European Drug Utilisation Research Group (EuroDURG) Conference, Szeged, Hungary, March 5, 2020.

\section{REFERENCES}

1. Ho PM, Spertus JA, Masoudi FA, et al. Impact of medication therapy discontinuation on mortality after myocardial infarction. Arch Intern Med. 2006;166(17):1842-47. doi:10.1001/ archinte.166.17.1842

2. Jackevicius CA, Li P, Tu JV. Prevalence, predictors, and outcomes of primary nonadherence after acute myocardial infarction. Circulation. 2008;117(8):1028-36. doi:10.1161/ CIRCULATIONAHA.107.706820

3. McGinnis BD, Olson KL, Delate TM, Stolcpart RS. Statin adherence and mortality in patients enrolled in a secondary prevention program. Am J Manag Care. 2009;15(10):689-95.

4. Rasmussen JN, Chong A, Alter DA. Relationship between adherence to evidence-based pharmacotherapy and long-term mortality after acute myocardial infarction. JAMA. 2007;297(2):177-86. doi: 10.1001/jama.297.2.177

5. Ho PM, Rumsfeld JS, Masoudi FA, et al. Effect of medication nonadherence on hospitalization and mortality among patients with diabetes mellitus. Arch Intern Med. 2006;166(17):1836-41. doi:10.1001/archinte.166.17.1836

6. Sokol MC, McGuigan KA, Verbrugge RR, Epstein RS. Impact of medication adherence on hospitalization risk and healthcare cost. Med Care. 2005;43(6): 521-30. doi:10.1097/01.mlr.00001636 41.86870.af
7. Roebuck MC, Liberman JN, Gemmill-Toyama M, Brennan TA. Medication adherence leads to lower health care use and costs despite increased drug spending. Health Aff (Millwood). 2011;30(1):91-99. doi:10.1377/ hlthaff.2009.1087

8. Bansilal S, Castellano JM, Garrido E, et al. Assessing the impact of medication adherence on long-term cardiovascular outcomes. J Am Coll Cardiol. 2016;68(8):789-801. doi: 10.1016/j. jacc.2016.06.005

9. Ibáñez L, Sabaté M, Vidal X, et al. Incidence of direct oral anticoagulant use in patients with nonvalvular atrial fibrillation and characteristics of users in 6 European countries (2008-2015): a crossnational drug utilization study. $\mathrm{Br}$ J Clin Pharmacol. 2019;85(11):2524-39. doi:10.1111/ bcp.14071

10. Rose AJ, Goldberg R, McManus DD, et al. Anticoagulant prescribing for non-valvular atrial fibrillation in the veterans health administration. J Am Heart Assoc. 2019;8(17):e012646. doi:10.1161/ JAHA.119.012646

11. Vrijens B, Heidbuchel H. Non-vitamin K antagonist oral anticoagulants: considerations on once- vs. twice-daily regimens and their potential impact on medication adherence. Europace. 2015;17(4):514-23. doi:10.1093/europace/euu311

12. Abdou JK, Auyeung V, Patel JP, Arya R. Adherence to long-term anticoagulation treatment, what is known and what the future might hold. $\mathrm{Br}$ J Haematol. 2016;174(1):30-42. doi:10.1111/bjh.14134

13. Shiga T, Naganuma M, Nagao T, et al. Persistence of non-vitamin $\mathrm{K}$ antagonist oral anticoagulant use in Japanese patients with atrial fibrillation: a single-center observational study. J Arrhythm. 2015;31(6):339-44. doi:10.1016/j. joa.2015.04.004

14. Mueller T, Alvarez-Madrazo S, Robertson C, Bennie M. Use of direct oral anticoagulants in patients with atrial fibrillation in Scotland: applying a coherent framework to drug utilisation studies. Pharmacoepidemiol Drug Saf. 2017;26(11):1378-86. doi:10.1002/pds.4272
15. Zhou M, Chang HY, Segal JB, Alexander GC, Singh S. Adherence to a novel oral anticoagulant among patients with atrial fibrillation. J Manag Care Spec Pharm. 2015;21(11):1054-1062. doi:10.18553/ jmcp.2015.21.11.1054

16. Manzoor BS, Lee TA, Sharp LK, Walton SM, Galanter WL, Nutescu EA. Real-world adherence and persistence with direct oral anticoagulants in adults with atrial fibrillation. Pharmacotherapy. 2017;37(10):1221-30. doi:10.1002/phar.1989

17. Harper P, Pollock D, Stephens M. Dabigatran persistence and adherence in New Zealand: a nationwide retrospective observational study. BMJ Open. 2018;8(4):e020212. doi:10.1136/ bmjopen-2017-020212

18. Zalesak M, Siu K, Francis K, et al. Higher persistence in newly diagnosed nonvalvular atrial fibrillation patients treated with dabigatran versus warfarin. Circ Cardiovasc Qual Outcomes. 2013;6(5):567-74. doi:10.1161/ CIRCOUTCOMES.113.000192

19. Liu C, Du X, Jiang C, et al. Long-term persistence with newly-initiated warfarin or non-VKA oral anticoagulant (NOAC) in patients with non-valvular atrial fibrillation: insights from the prospective china-AF registry. Med Sci Monit. 2019;25:2649-57. doi:10.12659/MSM.915875

20. Maura G, Pariente A, Alla F, Billionnet C. Adherence with direct oral anticoagulants in nonvalvular atrial fibrillation new users and associated factors: a French nationwide cohort study. Pharmacoepidemiol Drug Saf. 2017;26(11):1367-77. doi:10.1002/pds.4268

21. Hurtado-Navarro I, García-Sempere A, Rodríguez-Bernal C, Santa-Ana-Tellez Y, Peiró S, Sanfélix-Gimeno G. Estimating adherence based on prescription or dispensation information: impact on thresholds and outcomes: a real-world study with atrial fibrillation patients treated with oral anticoagulants in Spain. Front Pharmacol. 2018;9:1353. doi:10.3389/ fphar.2018.01353 
22. Pham PN, Brown JD. Real-world adherence for direct oral anticoagulants in a newly diagnosed atrial fibrillation cohort: does the dosing interval matter? BMC Cardiovasc Disord. 2019;19(1):64. doi:10.1186/s12872-019-1033-3

23. Shore S, Carey EP, Turakhia MP, et al. Adherence to dabigatran therapy and longitudinal patient outcomes: insights from the veterans health administration. Am Heart J. 2014;167(6):810-17. doi:10.1016/j. ahj.2014.03.023

24. Brown JD, Shewale AR, Talbert JC. Adherence to rivaroxaban, dabigatran, and apixaban for stroke prevention for newly diagnosed and treatment-naive atrial fibrillation patients: an update using 2013-2014 data. J Manag Care Spec Pharm. 2017;23(9):958-67. doi:10.18553/ jmcp.2017.23.9.958

25. Gomez-Lumbreras A, Cortes J, Giner-Soriano M, Quijada-Manuitt MA, Morros R. Characteristics of apixaban-treated patients, evaluation of the dose prescribed, and the persistence of treatment: a cohort study in Catalonia. J Cardiovasc Pharmacol Ther. 2018;23(6):494-501. doi:10.1177/1074248418778544

26. Han S, Jeong HS, Kim H, Suh HS. The treatment pattern and adherence to direct oral anticoagulants in patients with atrial fibrillation aged over 65. PLoS One. 2019;14(4):e0214666. doi:10.1371/journal. pone. 0214666

27. Gadkari AS, McHorney CA. Medication nonfulfillment rates and reasons: narrative systematic review. Curr Med Res Opin. 2010;26(3):683-705. doi:10.1185/03007990903550586

28. Fischer MA, Stedman MR, Lii J, et al. Primary medication non-adherence: analysis of 195,930 electronic prescriptions. J Gen Intern Med. 2010;25(4):284-90. doi:10.1007/s11606-010-1253-9

29. Shah NR, Hirsch AG, Zacker C, Taylor S, Wood GC, Stewart WF. Factors associated with first-fill adherence rates for diabetic medications: a cohort study. J Gen Intern Med. 2009;24(2):233-37. doi: $10.1007 / \mathrm{s} 11606-008-0870-\mathrm{z}$
30. Rodriguez-Bernal CL, Peiro S, Hurtado I, Garcia-Sempere A, SanfelixGimeno G. Primary nonadherence to oral anticoagulants in patients with atrial fibrillation: real-world data from a population-based cohort. J Manag Care Spec Pharm. 2018;24(5):440-48. doi:10.18553/ jmcp.2018.24.5.440

31. García-Gil Mdel M, Hermosilla E, Prieto-Alhambra D, et al. Construction and validation of a scoring system for the selection of high-quality data in a Spanish population primary care database (SIDIAP). Inform Prim Care. 2011;19(3) 135-45. doi:10.14236/jhi.v19i3.806

32. Gardarsdottir H, Souverein PC, Egberts TC, Heerdink ER. Construction of drug treatment episodes from drug-dispensing histories is influenced by the gap length. J Clin Epidemiol. 2010;63(4):422-27. doi:10.1016/j.jclinepi.2009.07.001

33. Masnoon N, Shakib S, Kalisch-Ellett L, Caughey GE. What is polypharmacy? A systematic review of definitions. BMC Geriatr. 2017;17(1):230. doi:10.1186/ s12877-017-0621-2

34. Tamblyn R, Eguale T, Huang A, Winslade N, Doran P. The incidence and determinants of primary nonadherence with prescribed medication in primary care: a cohort study. Ann Intern Med. 2014;160(7):441-50. doi:10.7326/M13-1705

35. Shore S, Ho PM, Lambert-Kerzner A, et al. Site-level variation in and practices associated with dabigatran adherence. JAMA. 2015;313(14):1443-50. doi:10.1001/ jama.2015.2761

36. Lauffenburger JC, Balasubramanian A, Farley JF, et al. Completeness of prescription information in US commercial claims databases. Pharmacoepidemiol Drug Saf. 2013;22(8):899-906. doi:10.1002/pds.3458

37. Shrank WH, Choudhry NK, Fischer MA, et al. The epidemiology of prescriptions abandoned at the pharmacy. Ann Intern Med. 2010;153(10):633-40. doi:10.7326/0003-4819-153-10-20101116000005
38. Grymonpre R, Cheang M, Fraser M, Metge C, Sitar DS. Validity of a prescription claims database to estimate medication adherence in older persons. Med Care. 2006;44(5):471-77. doi:10.1097/01.mlr.0000207817.32496.cb

39. Márquez-Contreras E, López García-Ramos L, Martell-Claros N, et al. Validation of the electronic prescription as a method for measuring treatment adherence in hypertension. Patient Educ Couns. 2018;101(9):1654-60. doi:10.1016/j. pec.2018.04.009

40. Ramos R, Balló E, Marrugat J, et al. Validity for use in research on vascular diseases of the SIDIAP (information system for the development of research in primary care): the EMMA study. Rev Esp Cardiol (Engl Ed). 2012;65(1):29-37. doi:10.1016/j.recesp.2011.07.017

41. Garcia-Gil M, Elorza J-M, Banque M, et al. Linking of primary care records to census data to study the association between socioeconomic status and cancer incidence in southern Europe: a nation-wide ecological study. PLoS One. 2014;9(10):e109706-e109706. doi:10.1371/ journal.pone.0109706

42. Recalde M, Manzano-Salgado CB, Díaz Y, et al. Validation of cancer diagnoses In electronic health records: results from the information system for research In primary care (SIDIAP) in northeast Spain. Clin Epidemiol. 2019;11:1015-24. doi:10.2147/CLEP.S225568

43. Forns J, Cainzos-Achirica M, Hellfritzsch M, et al. Validity of ICD-9 and ICD-10 codes used to identify acute liver injury: a study in three European data sources. Pharmacoepidemiol Drug Saf. 2019;28(7):965-75. doi:10.1002/pds.4803

44. Reynolds K, Muntner P, Cheetham TC, et al. Primary non-adherence to bisphosphonates in an integrated healthcare setting. Osteoporos Int. 2013;24(9):2509-17. doi:10.1007/s00198-013-2326-5 